Article

\title{
Polyethylene Glycol (PEG)-Treated Hydroponic Culture Reduces Length and Diameter of Root Hairs of Wheat Varieties
}

\author{
Arif Hasan Khan Robin *, Md. Jasim Uddin and Khandaker Nafiz Bayazid \\ Department of Genetics and Plant Breeding, Bangladesh Agricultural University, \\ Mymensingh 02202, Bangladesh; E-Mails: jasimpstu998@gmail.com (M.J.U.); \\ nafizbayazid@gmail.com (K.N.B.)
}

* Author to whom correspondence should be addressed; E-Mail: gpb21bau@bau.edu.bd; Tel.: +880-916-7401-7/2527; Fax: +880-916-1510.

Academic Editor: Leslie A. Weston

Received: 24 July 2015 / Accepted: 22 October 2015 / Published: 27 October 2015

\begin{abstract}
Wheat is an important cereal crop worldwide that often suffers from moisture deficits at the reproductive stage. Polyethylene glycol (PEG)-treated hydroponic conditions create negative osmotic potential which is compared with moisture deficit stress. An experiment was conducted in a growth chamber to study the effects of PEG on root hair morphology and associated traits of wheat varieties. Plants of 13 wheat varieties were grown hydroponically and three different doses of PEG $6000(w / v)$ : $0 \%$ (control), 0.3\% and $0.6 \%$ (less than -1 bar) were imposed on 60 days after sowing for 20 days' duration. A low PEG concentration was imposed to observe how initial low moisture stress might affect root hair development. PEG-treated hydroponic culture significantly decreased root hair diameter and length. Estimated surface area reduction of root hairs at the main axes of wheat plants was around nine times at the $0.6 \%$ PEG level compared to the control plants. Decrease in root hair diameter and length under PEG-induced culture decreased "potential" root surface area per unit length of main root axis. A negative association between panicle traits, length and dry weight and the main axis length of young roots indicated competition for carbon during their development. Data provides insight into how a low PEG level might alter root hair development.
\end{abstract}

Keywords: wheat; root hairs; root morphology; phytomer; PEG 


\section{Introduction}

Wheat is grown on over 216 million hectares of land, yielding 634 million tons worldwide by 30 million farmers [1]. In Bangladesh, wheat is the second most important cereal crop after rice. It grows in $11 \%$ of the cropped area in rabi season and yields around 1.0 million tons [1,2]. To fulfill domestic demand of cereals, Bangladesh requires importing 3.0 million tons of wheat every year to meet the yield gap [3]. Unfavorable environmental conditions including heat stress, drought stress, and salinity are the main reasons for over $52 \%$ of the difference between current and recorded wheat production [1] and a 55\% difference between average yields and yield potential [3]. To ensure future food security, the wheat production area needs expansion. Efforts are, therefore, required to overcome various limiting factors that shrink wheat production areas including abiotic stresses. In Bangladesh, drought stress which alone decreased cereal grain production by 3.5 million metric tons in the year 1994-1995 [4] is considered a more serious threat to crop production than floods and cyclones as its frequency has increased over the years [5]. The best option to meet yield gap through yield improvement and yield stability under drought stress conditions is to develop drought tolerant crop varieties. One important avenue for follow up is development of wheat varieties with an efficient root system which can exploit residual soil moisture in the dry season to overcome low to moderate water deficits in soil.

A better understanding of various plant developmental and physiological processes that ultimately influence yield determining factors is essential to breeding for specific, suboptimal environments $[6,7]$. Under a low to moderate level of soil water deficit, osmotic adjustment enables plants to maintain uptake activity in many species, and is ultimately the reason for maintenance of growth and optimum yield under drought $[8,9]$. Extensive research efforts over the last five decades revealed physiological mechanisms relevant to osmotic stress response of crop plants [8-13]. Awareness related to root morphology of annual crop plants, such as wheat, barley, or perennial forage grasses under limited water supply, has developed within the last 20 years [14-23]. However, little awareness has been created as to how root hairs get modified, and are possibly associated with crop yield under different levels of osmotic potential. In dry environments, large root systems of wheat capture more water and nitrogen to facilitate access to additional water for grain filling [23]. Osmotic stress results in significant genotypic variation for a number of morphological traits including root length, dry weight and root-shoot ratio [24]. In another study, osmotic stress is reported to suppress discrimination among genotypes for root length along with seed vigour index, germination percentage, shoot length, coleoptile length and osmotic membrane stability [25]. A thorough understanding of root systems and root hair morphology and their responses towards various degrees of drought is required for future wheat breeding programs. This study therefore planned to explore how Polyethylene glycol (PEG) treated hydroponic culture affects root hair development and associated traits. This study involved establishing experimental plants of wheat varieties hydroponically, imposing PEG-treatment and measuring root hairs, associated root morphology and panicle traits. PEG is a widely used chemical compound and maintains lower osmotic potential at a comparatively lower temperature under hydroponic culture [26,27]. Plants were grown at an osmotic potential of less than 1 bar for a longer duration of 20 days. 


\section{Results}

\subsection{Treatment Effect}

Number of adventitious roots per tiller recorded the highest under $0.6 \%$ level, which was significantly different from control ( $p=0.035$, Table 1). Root hair length and diameter of the root hairs gradually decreased with increasing levels of PEG $(p<0.001$, Table 1). Length of root hairs greatly reduced at $0.6 \%$ PEG level compared to control and 0.3\% PEG level $(p<0.001$, Table 1). Even though root hair density was slightly increased under osmotic stress, estimated overall surface area provided solely by the root hairs per $\mathrm{mm}^{2}$ main axis was about nine times less at $0.6 \%$ PEG level compared to control, due to a severe decrease in diameter and length of root hairs $(p=0.003$, Table 1$)$. Second principal component (PC2) explained $17.5 \%$ data variation, which indicated a contrast between the three treatments for root hair density with other root hair traits like: diameter, length and surface area (Table 2, $p<0.001$ ). PC2 clearly revealed that plants under $0.6 \%$ PEG level yielded much reduced surface area with simultaneous decrease in root hair diameter and root hair length (Table 2). PC scores indicated that $0.6 \%$ PEG level had average negative PC scores where the other two treatments had average positive PC scores (Table 2).

Table 1. Variation in morphological characters of 13 wheat varieties 20 days after treatment due to three different PEG treatments. Data represents average of 39 replicates under each treatment. SEM, standard error of mean; p, probability of statistical significance.

\begin{tabular}{|c|c|c|c|c|c|}
\hline $\begin{array}{l}\text { Treatments } \\
\text { (\% PEG) }\end{array}$ & $\begin{array}{c}\text { Number of } \\
\text { Adventitious } \\
\text { Roots per Tiller }\end{array}$ & $\begin{array}{c}\text { Root Hair } \\
\text { Density } \\
\left(\text { no. } \mathrm{mm}^{-2}\right) \\
\end{array}$ & $\begin{array}{c}\text { Root Hair } \\
\text { Diameter }(\mu)\end{array}$ & $\begin{array}{l}\text { Root Hair } \\
\text { Length }(\mu)\end{array}$ & $\begin{array}{l}\text { Root Hair Surface } \\
\text { Area per } \mathbf{m m}^{2} \\
\text { Main Axis }\left(\mathbf{m m}^{2}\right)\end{array}$ \\
\hline 0 & 10.2 & 70.8 & 7.75 & 367 & 0.725 \\
\hline 0.3 & 9.3 & 96.2 & 5.90 & 341 & 0.592 \\
\hline 0.6 & 11.1 & 106 & 4.04 & 59 & 0.085 \\
\hline SEM & 0.37 & 7.9 & 0.24 & 30.9 & 0.071 \\
\hline$p$ value & 0.035 & 0.12 & $<0.001$ & $<0.001$ & $<0.001$ \\
\hline
\end{tabular}

Table 2. Principal component analysis (PCA) of selected morphological traits of wheat varieties under PEG-treated hydroponic culture. PC, principal component; $p$, statistical significance; Pr, root bearing phytomer.

\begin{tabular}{cccc}
\hline Traits & PC1 & PC2 & PC3 \\
\hline Live leaves (no.) & 0.396 & -0.117 & -0.096 \\
Total number of roots per tiller & 0.394 & -0.175 & -0.021 \\
Main axis length at Pr1 $(\mathrm{cm})$ & 0.109 & 0.192 & -0.358 \\
Main axis length at Pr2 $(\mathrm{cm})$ & 0.164 & 0.131 & -0.502 \\
Diameter of root hair $(\mu)$ & 0.115 & 0.531 & 0.085 \\
Length of root hair $(\mu)$ & 0.161 & 0.543 & 0.109 \\
Root hair density (no. $\left.\mathrm{mm}^{-2}\right)$ & 0.291 & -0.254 & 0.008 \\
Root hair surface area $\mathrm{mm}^{-2}$ axis & 0.231 & 0.473 & 0.137 \\
Panicle length $(\mathrm{cm})$ & 0.297 & -0.090 & 0.470 \\
Panicle dry weight $(\mathrm{mg})$ & 0.232 & -0.050 & 0.485 \\
\hline
\end{tabular}


Table 2. Cont.

\begin{tabular}{cccc}
\hline Traits & PC1 & PC2 & PC3 \\
\hline Root dry weight per tiller $(\mathrm{mg})$ & 0.393 & -0.159 & -0.109 \\
Shoot dry weight per tiller $(\mathrm{mg})$ & 0.202 & 0.005 & -0.304 \\
\% variation explained & 31 & 17.5 & 13.1 \\
$p$ (treatment) & 0.27 & $<0.001$ & 0.292 \\
$p$ (variety) & $<0.001$ & 0.222 & $<0.001$ \\
$p$ (treatment $\times$ variety) & 0.169 & 0.982 & $<0.001$ \\
\hline \multicolumn{5}{c}{ Mean PC scores for treatment } \\
\hline 0.0\% PEG & $0.23 \pm 0.22$ & $0.77 \pm 0.25$ & $0.13 \pm 0.14$ \\
0.3\% PEG & $0.02 \pm 0.22$ & $0.28 \pm 0.25$ & $0.09 \pm 0.15$ \\
0.6\% PEG & $-0.26 \pm 0.22$ & $-1.02 \pm 0.25$ & $-0.17 \pm 0.14$ \\
\hline \multicolumn{5}{c}{ Mean PC scores for variety } & \\
\hline Shotabdi & $0.91 \pm 0.51$ & $-0.09 \pm 0.58$ & $0.60 \pm 0.34$ \\
Shourov & $-0.61 \pm 0.48$ & $-0.49 \pm 0.55$ & $1.55 \pm 0.32$ \\
Sufi & $-1.92 \pm 0.48$ & $0.36 \pm 0.55$ & $-0.55 \pm 0.32$ \\
Prodeep & $3.81 \pm 0.44$ & $-1.51 \pm 0.51$ & $0.59 \pm 0.29$ \\
Bijoy & $-0.87 \pm 0.44$ & $0.88 \pm 0.51$ & $-0.07 \pm 0.29$ \\
BARI gom25 & $1.87 \pm 0.44$ & $-0.22 \pm 0.51$ & $-0.30 \pm 0.29$ \\
BARI gom26 & $-0.23 \pm 0.44$ & $0.11 \pm 0.51$ & $-0.29 \pm 0.29$ \\
BARI gom27 & $-1.01 \pm 0.44$ & $-0.38 \pm 0.51$ & $0.45 \pm 0.29$ \\
BARI gom28 & $-0.99 \pm 0.44$ & $0.21 \pm 0.51$ & $-0.07 \pm 0.29$ \\
Kheri & $0.43 \pm 0.44$ & $0.49 \pm 0.51$ & $-0.78 \pm 0.29$ \\
Sonalika & $-0.90 \pm 0.44$ & $0.14 \pm 0.51$ & $-0.24 \pm 0.29$ \\
Kanchan & $-0.37 \pm 0.44$ & $0.27 \pm 0.51$ & $-0.42 \pm 0.29$ \\
Akbar & $-0.15 \pm 0.48$ & $0.36 \pm 0.55$ & $-0.26 \pm 0.32$ \\
\hline & & &
\end{tabular}

\subsection{Varietal Difference}

A remarkable number of morphological traits were significant among the 13 wheat varieties including: number of live leaves, number of root bearing phytomers, number of adventitious roots, average number of roots per phytomer, number of seminal roots per tiller, main axes length at Pr1 and Pr2; main axes diameter, root hair diameter and root dry weight per tiller (Table 3). First principal component (PC1) explaining 30\% data variation indicated a significant contrast among varieties for number of live leaves, number of adventitious roots, root hair diameter, surface area of root hairs, panicle length and root and shoot dry weights per tiller (Table 3). PC1can be regarded as "size PC". The variety Prodeep which yielded the largest biomass along with the highest number of leaves and adventitious roots obtained the largest PC score compared to Sufi and BARI gom 27 which had the lowest number of live leaves and root dry weight, respectively (Table 3). 
Table 3. Variation in different morphological characters of 13 wheat varieties on 20 days after PEG- treatment (DAT). Data represents average of nine replicates on 12 DAT from three treatments. Pr, root bearing phytomer; SEM, standard error of mean; $p$, statistical significance.

\begin{tabular}{|c|c|c|c|c|c|c|c|c|c|c|}
\hline Variety & $\begin{array}{l}\text { Live Leaves } \\
\quad \text { (No.) }\end{array}$ & $\begin{array}{c}\text { No. of Root } \\
\text { Bearing Phytomer }\end{array}$ & $\begin{array}{c}\text { No. of } \\
\text { Adventitious } \\
\text { Roots per Tiller } \\
\end{array}$ & $\begin{array}{c}\text { Average no. } \\
\text { of Roots per } \\
\text { Phytomer }\end{array}$ & $\begin{array}{c}\text { No. of } \\
\text { Seminal } \\
\text { Roots } \\
\end{array}$ & $\begin{array}{c}\text { Main Axis } \\
\text { Length at } \\
\text { Pr1 (cm) } \\
\end{array}$ & $\begin{array}{c}\text { Main Axis } \\
\text { Length at } \\
\text { Pr2 }(\mathrm{cm}) \\
\end{array}$ & $\begin{array}{c}\text { Main Axis } \\
\text { Diameter } \\
(\mathbf{m m}) \\
\end{array}$ & $\begin{array}{c}\text { Root Hair } \\
\text { Density } \\
\left(\text { No. } \mathbf{m m}^{-2}\right) \\
\end{array}$ & $\begin{array}{c}\text { Root Dry } \\
\text { Weight } \\
\text { (mg) }\end{array}$ \\
\hline Shotabdi & 5.3 & 5.77 & 11.7 & 2.01 & 3.78 & 10.2 & 16.9 & 0.57 & 34.7 & 65 \\
\hline Shourov & 4.0 & 3.89 & 7.3 & 1.89 & 3.00 & 12.8 & 12.4 & 0.55 & 21.9 & 43 \\
\hline Sufi & 3.0 & 5.22 & 9.2 & 1.77 & 2.56 & 12.1 & 17.6 & 0.53 & 14.5 & 38 \\
\hline Prodeep & 7.8 & 7.00 & 17.8 & 2.52 & 4.56 & 11.5 & 20.0 & 0.71 & 76.7 & 134 \\
\hline Bijoy & 3.4 & 4.89 & 9.4 & 1.95 & 2.44 & 13.2 & 17.2 & 0.60 & 28.5 & 53 \\
\hline BARI gom 25 & 6.2 & 6.44 & 13.8 & 2.12 & 4.56 & 17.4 & 23.6 & 0.66 & 31.6 & 81 \\
\hline BARI gom 26 & 4.1 & 4.89 & 10.0 & 2.03 & 3.22 & 13.2 & 19.9 & 0.51 & 26.3 & 54 \\
\hline BARI gom 27 & 4.1 & 4.33 & 9.2 & 2.14 & 3.00 & 8.9 & 17.3 & 0.49 & 17.1 & 37 \\
\hline BARI gom 28 & 3.9 & 4.33 & 7.7 & 1.78 & 3.11 & 15.5 & 16.3 & 0.59 & 10.6 & 67 \\
\hline Kheri & 5.7 & 5.11 & 9.7 & 1.88 & 3.00 & 28.2 & 21.0 & 0.57 & 34.5 & 62 \\
\hline Sonalika & 3.6 & 4.78 & 8.4 & 1.78 & 2.78 & 19.0 & 16.2 & 0.52 & 33.2 & 46 \\
\hline Kanchan & 4.7 & 5.00 & 9.0 & 1.79 & 2.78 & 17.5 & 19.1 & 0.47 & 26.7 & 41 \\
\hline Akbar & 4.2 & 5.22 & 9.3 & 1.81 & 3.44 & 14.9 & 24.2 & 0.51 & 43.2 & 44 \\
\hline SEM & 0.16 & 0.12 & 0.37 & 0.035 & 0.11 & 0.96 & 0.75 & 0.012 & 3.12 & 3.84 \\
\hline$p$ value & $<0.001$ & $<0.001$ & $<0.001$ & $<0.001$ & 0.001 & 0.03 & 0.02 & 0.003 & 0.004 & $<0.001$ \\
\hline
\end{tabular}




\subsection{Treatment-Variety Interaction}

Third principal component (PC3), which explains 13.1\% data variation, indicated a significant contrast for varieties and variety-treatment interaction. The panicle length and panicle dry weight had positive coefficients and main axes length at $\operatorname{Pr} 1 \& \operatorname{Pr} 2$ and shoot dry weight had negative coefficients in PC3 (Table 2). Analysis of variance indicated that panicle length (Figure $1, p<0.001$ ), panicle dry weight (Figure 2, $p<0.001)$ and main axis length at $\operatorname{Pr} 2(p<0.001)$ were significant for variety-treatment. PC3 indicated a "competition between roots and panicle of the varieties for dry matter partitioning" (Table 2). Shourov, Shotabdi, Prodeep, BARI gom 27 which are high yielding inbred varieties of wheat had the positive PC scores compared to low yielding varieties and landrace, Kheri, which obtained the lowest PC score (Table 2).

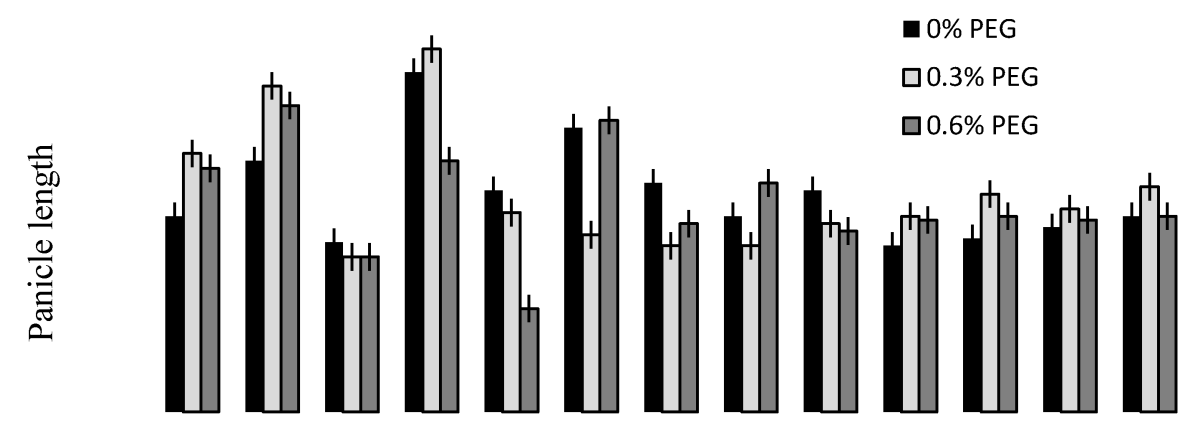

Varieties

Figure 1. Panicle length $(\mathrm{cm})$ of 13 wheat varieties with three different PEG treatments. PEG treatment was imposed for 60 days after sowing for 20 days.

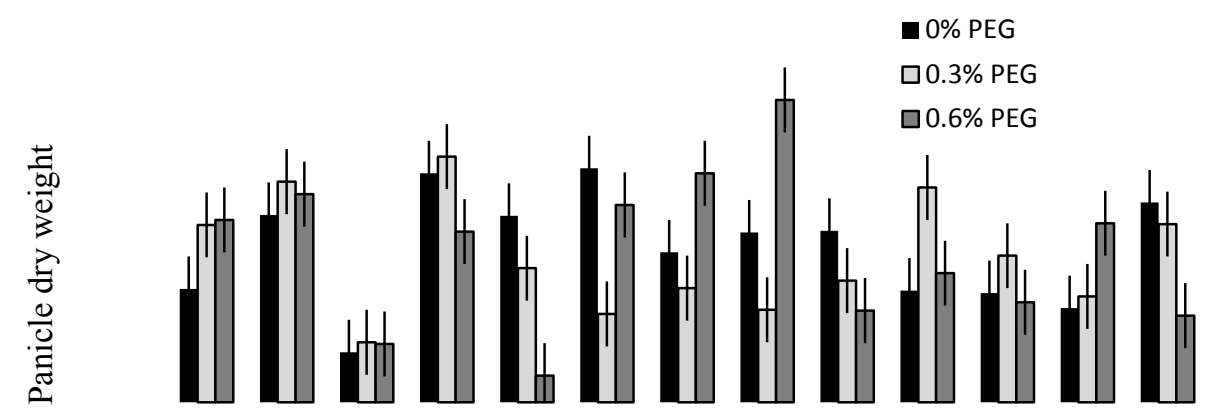

Varieties

Figure 2. Panicle dry weight (mg) of 13 wheat varieties with three different PEG treatments. PEG treatment was imposed for 60 days after sowing for 20 days. 


\subsection{Discussion}

\subsubsection{Root Surface Area Reduction under Osmotic Stress}

In this study, the estimated reduction of root surface area of an individual root was related to reduction of diameter and length of root hairs (Table 1, PC2 in Table 2). Reduction of root surface area hampers uptake activity of the plants as available root surface area is directly related to absorption of nutrients, especially phosphorus and water from the soil by the crop plants [28,29]. With confidence, root hairs are valuable tools for nutrient acquisition under all circumstances. Morphology of root hairs differs under different abiotic stresses. For example, Jupp and Newman [30], under drought treatment in Lolium perenne, recorded that root hairs disappeared from around $50 \%$ and $80 \%$ plants after three and eight days, respectively.

\subsubsection{Increased Total Number of Roots per Tiller}

An increase in total number of roots per tiller at $0.6 \%$ PEG level compared to control had some similarity to the findings of a previous study of the same group of authors under salinity stress (Table 1, unpublished data). In their study, number of new root appearances at the youngest root bearing phytomer increased compared to control. These results suggested that abiotic stress primarily affects leaf growth and degrades some carbonaceous and nitrogenous compounds like chlorophyll [31,32], and part of $\mathrm{C}$ and $\mathrm{N}$ released from the bio-molecular de-gradation are possibly transported to the root system for additional root growth.

\subsubsection{Trait Association: Root Traits with Panicle Traits}

Grain yield is a complex and quantitative trait. It is unrealistic to make any straightforward comment that grain yield is directly related to a particular trait only, but in previous studies root hair length was related to grain yield stability [33]. PC2 revealed that root surface area reduction due to treatment effect had a positive association with root hair length and diameter. Root hairs with only $2 \%$ of the total carbon required for root construction [34] can contribute total root surface area by many folds, up to $74 \%$ of total root surface area of a developed root of a rice plant [35]. In a previous study with barley, longer and denser root hairs yielded a three times higher root surface area [36]. Root hairs not only provide additional surface area to the plants for ion acquisition but also help in rhizosheath formation [28], mediate extra release of organic acids [37,38] and interact with microbial association [39] and, thereby, play an important role in crop yield which deserves further intensive investigation.

\subsubsection{Varietal Differences}

Significant intra and inter-species variation exists for the types and lengths of root hairs [40-43]. Genotypic variations in root hair density along with some other root traits suggested that those traits can be improved by selection (Table 3). PC3 indicated a contrast between panicle traits with the main root axis length for significant varietal difference. Positive and negative PC scores between high yielding wheat varieties, Prodeep, Shourov, Shotabdi and BARI gom27, and the lowest yielding landrace Kheri along with other varieties suggested that high yielding varieties under lower osmotic 
potential partition comparatively high dry matter to the panicle and less to the roots (see Figures 1 and 2, Table 2). Varietal variation in $\mathrm{C}, \mathrm{N}$ and dry matter portioning among roots, stem and ear of wheat varieties is evident in the literature $[44,45]$.

\section{Experimental Section}

\subsection{Plant Culture and Management}

The experiment was conducted at the Department of Genetics and Plant Breeding, Bangladesh Agricultural University for the period between August 2013 and February 2014. Seeds of 13 elite wheat varieties were collected from the Wheat Research Centre of the Bangladesh Agricultural Research Institute, Gazipur (Table 4). Seeds were germinated in clean tap water floated in foam net inside the plastic trays in a growth chamber. Around 200 seeds were germinated per tray for each variety in order to select 18 healthy seedlings with synchronized leaf appearance in hydroponic nutrient solution at transplanting. Seed germination process took 5-7 days. Seedlings were transplanted in hydroponic solution following a completely randomized design with three treatments and six replicates per treatment for each of the 13 varieties. An individual plant was considered as a single replicate as root variables were measured in individual plants. There were 18 individual trays for setting up the whole experiment, six trays for each treatment. Each tray contained 13 plants, one from each variety. Plants were cultured at $20 \pm 2{ }^{\circ} \mathrm{C}$ temperature and at $50 \pm 2$ PPFD (photosynthetic photon flux density) light intensity with cool white fluorescent lamps in a 12:12 h day:night cycle. Leaf appearance interval of all varieties was monitored for two weeks and that was calculated at around 10 days $\left(90{ }^{\circ} \mathrm{C}\right.$ days). Plants were fed with following nutrient solution: $1 \mathrm{mM} \cdot \mathrm{NH}_{4} \mathrm{NO}_{3}$, $0.6 \mathrm{mM} \cdot \mathrm{NaH}_{2} \mathrm{PO} 4 \cdot \mathrm{H}_{2} \mathrm{O}, \quad 0.6 \mathrm{mM} \cdot \mathrm{MgCl}_{2} \cdot \mathrm{H}_{2} \mathrm{O}, \quad 0.3 \mathrm{mM} \cdot \mathrm{K}_{2} \mathrm{SO}_{4}, \quad 0.3 \mathrm{mM} \cdot \mathrm{CaCl}_{2} \cdot \mathrm{H}_{2} \mathrm{O}, \quad 50 \mu \mathrm{M} \cdot \mathrm{H}_{3} \mathrm{BO}_{3}$, $90 \mu \mathrm{M} \cdot \mathrm{Fe}-\mathrm{EDTA}, \quad 9 \mu \mathrm{M} \cdot \mathrm{MnSO}_{4} \cdot 4 \mathrm{H} 2 \mathrm{O}, \quad 0.7 \mu \mathrm{M} \cdot \mathrm{ZnSO}_{4} \cdot 7 \mathrm{H}_{2} \mathrm{O}, \quad 0.3 \mu \mathrm{M} \cdot \mathrm{CuSO}_{4} \cdot 5 \mathrm{H}_{2} \mathrm{O}$, $0.1 \mu \mathrm{M} \cdot \mathrm{NaMoO}_{4} \cdot 2 \mathrm{H}_{2} \mathrm{O}$ dissolved in water [40]. The nutrient solution was refreshed weekly. All 234 plants were under similar management until they were 60 days old. There were 4-6 live leaves, 3-6 seminal roots and 6-12 adventitious roots per main tiller 60 days after transplantation depending on varieties $(p<0.001)$. Three different polyethylene glycol (PEG 6000, Sigma-Aldrich, Steinheim, Germany) treatments were imposed when the plants were 60 days old. Those were: $0 \%$ (control), $0.3 \%$ and $0.6 \%$ PEG levels. The highest level of PEG $0.6 \%$ can potentially create an osmotic potential less than one bar at $20{ }^{\circ} \mathrm{C}$ [27]. Even though PEG concentrations are low, however intuitively, these low concentrations of PEG can cause a significant reduction in root hydraulic conductivity, and, therefore, significant water stress, depending on the varieties of wheat. 
Table 4. List of 13 wheat varieties used for studying root hairs' development and associated traits under PEG-treated hydroponic culture.

\begin{tabular}{cc}
\hline Variety & Seed Source \\
\hline Shotabdi & \\
Shourov & \\
Sufi & \\
Prodeep & \\
Bijoy & Wheat Research Centre \\
BARI gom25 & of Bangladesh \\
BARI gom26 & Agricultural Research \\
BARI gom27 & Institute \\
BARI gom28 & \\
Kheri & \\
Sonalika & \\
Kanchan & \\
Akbar & \\
\hline
\end{tabular}

\subsection{Measurements and Data Collection}

Data were recorded on 20 days and 40 days after the PEG treatment by two separate destructive harvests. Three individual plants out of six from each variety $\times$ treatment combination were destructively harvested 20 days after treatment, and the remaining three 40 days after treatment. Number of live leaves per main tiller was recorded on the same day. Measurements of root traits were carried out during the destructive harvest. Root measurements include number of root bearing phytomers, number of adventitious roots, mean number of roots per phytomer, number of seminal roots, main axis length at the root bearing phytomer position (Pr) 1, 2, 3, and 4 (youngest root bearing phytomer was considered as reference point), main axis diameter at $\operatorname{Pr} 1$, number of root hairs per mm main axis at $\operatorname{Pr} 1$, length and diameter of the root hairs at Pr1. Diameter of the main axis, number of root hairs per mm main axis, length and diameter of root hair were measured at $100 \times$ magnification under a light microscope. A safranin solution of $0.5 \%$ prepared in $50 \%$ alcohol was used for staining root hairs. Shoots and roots of the plants at the destructive harvest were dried in an air draft oven for $72 \mathrm{~h}$ at $60{ }^{\circ} \mathrm{C}$ before recording their dry weights. Panicle length was recorded at the second destructive harvest 40 days after treatment, when plants were 100 days old. Dry weights of the panicles were recorded after $72 \mathrm{~h}$ drying at $60{ }^{\circ} \mathrm{C}$ in an air draft oven.

\subsection{Estimation of Root Hair Density and Root Hair Surface Area}

To estimate root hair density in no. $\mathrm{mm}^{-2}$ main axis, individual main axis was considered as cylinders. Then, the surface area of the main axis per mm length was calculated as: $\pi \times \mathrm{D}(\mathrm{mm}) \times 1$ $\mathrm{mm}$ length. Number of root hairs per $\mathrm{mm}^{2}$ surface area was obtained using the following equation:

$$
\text { Root hair density (no. } \left.\mathrm{mm}^{-2}\right)=\frac{\text { Number of root hairs counted per mm length of main axis }}{\text { Surface area of main axis for per mm length of main axis }}
$$

Surface area produced by the root hairs at different PEG levels was calculated from the following equation: 


$$
\text { Root hair surface area }\left(\mathrm{mm}^{2}\right)=\text { Root hair density }\left(\text { no. } \mathrm{mm}^{-2}\right) \times \pi \times \text { RHD } \times \text { RHL }
$$

where RHD and RHL respectively represent root hair diameter and root hair length.

\subsection{Statistical Analyses}

Analysis of variance was carried out following a generalized linear model, using MINITAB 16 statistical software package (Minitab Inc., State College, PA, USA) to find variations among treatments, varieties and treatment $\times$ varieties. To test the significant variations among the measured variables, a user defined model was used where the replications within treatment were the error term. Principal component analysis was carried out for some selected traits, the majority of which accounted for either a significant treatment effect or treatment $\times$ varieties effect. Analysis of variance of the PC scores was carried out for treatment and variety effects following a generalized linear model.

\section{Conclusions}

One objective of this study was to measure development of root hairs at the reproductive stage under PEG-treated hydroponic culture. This study found that PEG-treated culture decreased the length and diameter of root hairs. Reduction of root hair diameter and root hair length reduced the root surface area of an individual root (Table 2, PC2 in Table 3). In addition, this study revealed a contrast between main axis length and panicle traits with significant differences among varieties, which suggested competition in dry matter partitioning. As low exposure of PEG alters the diameter and length of root hairs, in future experimentation, it will be important to observe how these alterations are associated with growth, development and yield of the wheat varieties under low moisture stress. Moreover, data relevant to root hydraulic conductance or leaf water potential against each of the PEG levels would provide further validation of the experimental results.

\section{Acknowledgments}

This research was supported by the Bangladesh Agriculture University Research System (BAURES) Grant No. 2013/18/BAU.

\section{Author Contributions}

Arif Hasan Khan Robin planned and designed experiments; analyzed data and written the full manuscript. Md. Jasim Uddin and Khandaker Nafiz Bayazid assisted Arif Hasan Khan Robin managing plants and data collection.

\section{Conflicts of Interest}

The authors declare no conflict of interest.

\section{References}

1. FAOSTAT Data, 2007-Food and Agricultural Commodities Production; FAO: Rome, Italy, 2012. Available online: http://faostat.fao.org (accessed on 4 November 2012). 
2. Anonymous. Statistical Year Book of Bangladesh-2010, Bangladesh Bureau of Statistics, Planning Division, Ministry of Planning; Government of the People's Republic of Bangladesh: Dhaka, Bangladesh, 2011.

3. Hossain, A.; Silva, J.A.T. Wheat production in Bangladesh: Its future in the light of global warming. AoB Plants 2013, 5, 42, doi:10.1093/aobpla/pls042.

4. Rahman, A.; Biswas, P.R. Devours resources. Dhaka Cour. 1995, 11, 7-8.

5. Shahid, S.; Behrawan, H. Drought risk assessment in the western part of Bangladesh. Nat. Hazards 2008, 46, 391-413.

6. Blum, A. Genetic and physiological relationships in plant breeding for drought resistance. Agric. Water Manag. 1983, 7, 195-205.

7. Turner, N.C.; Wright, G.C.; Siddique, K.H.M. Adaptation of grain legumes (pulses) to water-limited environments. Adv. Agron. 2001, 71, 194-233.

8. Gunasekera, D.; Berkowitz, G.A. Evaluation of contrasting cellular-level acclimation responses to leaf water deficits in three wheat genotypes. Plant Sci. 1992, 86, 1-12.

9. Morgan, J.M. Osmoregulation and water stress in higher plants. Annu. Rev. Plant Physiol. 1984, 35, 299-319.

10. Bray, E.A. Molecular responses to water deficit. Plant Physiol.1993, 103, 1035-1040.

11. Manavalan, L.P.; Guttikonda, S.K.; Tran, L.S.P.; Nguyen, H.T. Physiological and molecular approaches to improve drought resistance in soybean. Plant Cell Physiol. 2009, 50, 1260-1276.

12. Turner, N.C. Adaptation to water deficits: A changing perspective. Funct. Plant Biol. 1986, 13, 175-190.

13. Turner, N.C.; Jones, M.M. Turgor Maintenance by Osmotic Adjustment: A Review and Evaluation. In Adaptation of Plants to Water and High Temperature Stress; Turner, N., Kramer, P., Eds.; John Wiley \& Sons, Inc., the University of Michigan: Ann Arbor, MI, USA, 1980; pp. 87-103.

14. Bengough, A.G.; Bransby, M.F.; Hans, J.; McKenna, S.J.; Roberts, T.J.; Valentine, T.A. Root responses to soil physical conditions; growth dynamics from field to cell. J. Exp. Bot. 2006, 57, 437-447.

15. Bengough, A.G.; McKenzie, B.; Hallett, P.; Valentine, T. Root elongation, water stress, and mechanical impedance: A review of limiting stresses and beneficial root tip traits. J. Exp. Bot. 2011, 62, 59-68.

16. Brown, L.K.; George, T.S.; Thompson, J.A.; Wright, G.; Lyon, J.; Dupuy, L.; Hubbard, S.; White, P. What are the implications of variation in root hair length on tolerance to phosphorus deficiency in combination with water stress in barley (Hordeum vulgare L.)? Ann. Bot. 2012, 110, 319-328.

17. Crush, J.; Easton, H.; Waller, J.; Hume, D.; Faville, M. Genotypic variation in patterns of root distribution, nitrate interception and response to moisture stress of a perennial ryegrass (Lolium perenne L.) mapping population. Grass Forage Sci. 2007, 62, 265-273.

18. Ehdaie, B.; Layne, A.P.; Waines, J.G. Root system plasticity to drought influences grain yield in bread wheat. Euphytica 2012, 186, 219-232.

19. Ji, H.; Liu, L.; Li, K.; Xie, Q.; Wang, Z.; Zhao, X.; Li, X. PEG-mediated osmotic stress induces premature differentiation of the root apical meristem and outgrowth of lateral roots in wheat. $J$. Exp. Bot. 2014, 65, 4863-4872. 
20. Maggio, A.; Hasegawa, P.M.; Bressan, R.A.; Consiglio, M.F.; Joly, R.J. Review: Unravelling the functional relationship between root anatomy and stress tolerance. Funct. Plant Biol. 2001, 28, 999-1004.

21. Manschadi, A.M.; Christopher, J.; Hammer, G.L.; The role of root architectural traits in adaptation of wheat to water-limited environments. Funct. Plant Biol. 2006, 33, 823-837.

22. Manschadi, A.M.; Hammer, G.L.; Christopher, J.T. Genotypic variation in seedling root architectural traits and implications for drought adaptation in wheat (Triticum aestivum L.). Plant Soil 2008, 303, 115-129.

23. Palta, J.A.; Chen, X.; Milroy, S.P.; Rebetzke, G.J.; Dreccer, M.F.; Watt, M. Large root systems: Are they useful in adapting wheat to dry environments? Funct. Plant Biol. 2011, 38, 347-354.

24. Rauf, M.; Munir, M.; ul Hassan, M.; Ahmad, M.; Afzal, M. Performance of wheat genotypes under osmotic stress at germination and early seedling growth stage. Afr. J. Biotechnol. 2007, 6, 971-975.

25. Dhanda, S.; Sethi, G.; Behl, R. Indices of drought tolerance in wheat genotypes at early stages of plant growth. J. Agron. Crop Sci. 2004, 190, 6-12.

26. Davidson, D.; Chevalier, P. Influence of polyethylene glycol-induced water deficits on tiller production in spring wheat. Crop Sci. 1987, 27, 1185-1187.

27. Michel, B.E.; Kaufmann, M.R. The osmotic potential of polyethylene glycol 6000. Plant Physiol. 1973, 51, 914-916.

28. Haling, R.E.; Brown, L.K.; Bengough, A.G.; Young, I.M.; Hallett, P.D.; White, P.J.; George, T.S. Root hairs improve root penetration, root-soil contact, and phosphorus acquisition in soils of different strength. J. Exp. Bot. 2013, 64, 3711-3721.

29. Haling, R.E.; Brown, L.K.; Bengough, A.G.; Valentine, T.A.; White, P.J.; Young, I.M.; George, T.S. Root hair length and rhizosheath mass depend on soil porosity, strength and water content in barley genotypes. Planta 2014, 239, 643-651.

30. Jupp, A.; Newman, E. Morphological and anatomical effects of severe drought on the roots of Lolium perenne L. New Phytol. 1987, 105, 393-402.

31. Khanna-Chopra, R. Leaf senescence and abiotic stresses share reactive oxygen species-mediated chloroplast degradation. Protoplasma 2012, 249, 469-481.

32. Munné-Bosch, S.; Alegre, L. Die and let live: Leaf senescence contributes to plant survival under drought stress. Funct. Plant Biol. 2004, 31, 203-216.

33. Gahoonia, T.S.; Nielsen, N.E. Barley genotypes with long root hairs sustain high grain yields in low-P field. Plant Soil 2004, 262, 55-62.

34. Röhm, M.; Werner, D. Isolation of root hairs from seedlings of Pisum sativum. Identification of root hair specific proteins by in situ labeling. Physiol. Plant. 1987, 69, 129-136.

35. Robin, A.H.K.; Saha, P.S. Morphology of lateral roots of twelve rice cultivars of Bangladesh: Dimension increase and diameter reduction in progressive root branching at the vegetative stage. Plant Root 2015, 9, 34-42.

36. Gahoonia, T.S.; Nielsen, N.E. Variation in root hairs of barley cultivars doubled soil phosphorus uptake. Euphytica 1997, 98, 177-182.

37. Gahoonia, T.S.; Nielsen, N.E.; Joshi, P.A.; Jahoor, A. A root hairless barley mutant for elucidating genetic of root hairs and phosphorus uptake. Plant Soil 2001, 235, 211-219. 
38. Narang, R.A.; Bruene, A.; Altmann, T. Analysis of phosphate acquisition efficiency in different Arabidopsis accessions. Plant Physiol. 2000, 124, 1786-1799.

39. Brown, L.K.; George, T.S.; Barrett, G.E.; Hubbard, S.F.; White, P.J. Interactions between root hair length and arbuscular mycorrhizal colonisation in phosphorus deficient barley (Hordeum vulgare). Plant Soil 2013, 372, 195-205.

40. Robin, A.H.K.; Uddin, M.J.; Afrin, S.; Paul, P.R. Genotypic variations in root traits of wheat varieties at phytomer level. J. Bangladesh Agric. Univ. 2014, 12, 45-54.

41. Caradus, J. Selection for root hair length in white clover (Trifolium repens L.). Euphytica 1979, 28, 489-494.

42. Haling, R.E.; Richardson, A.E.; Culvenor, R.A.; Lambers, H.; Simpson, R.J. Root morphology, root-hair development and rhizosheath formation on perennial grass seedlings is influenced by soil acidity. Plant Soil 2010, 335, 457-468.

43. Haling, R.E.; Simpson, R.J.; Delhaize, E.; Hocking, P.J.; Richardson, A.E. Effect of lime on root growth, morphology and the rhizosheath of cereal seedlings growing in an acid soil. Plant Soil 2010, 327, 199-212.

44. Nicolas, M.E.; Lambers, H.; Simpson, R.J.; Dalling, M.J. Effect of drought on metabolism and partitioning of carbon in two wheat varieties differing in drought-tolerance. Ann. Bot. 1985, 55, 727-742.

45. Nicolas, M.E.; Simpson, R.J.; Lambers, H.; Dalling, M.J. Effects of drought on partitioning of nitrogen in two wheat varieties differing in drought-tolerance. Ann. Bot. 1985, 55, 743-754.

(C) 2015 by the authors; licensee MDPI, Basel, Switzerland. This article is an open access article distributed under the terms and conditions of the Creative Commons Attribution license (http://creativecommons.org/licenses/by/4.0/). 